\title{
LEONARDO DA VINCI'S INFLUENCE ON RENAISSANCE ANATOMY
}

\author{
by
}

\author{
KENNETH D. KEELE
}

LeONARDO DA Vinci has been described as the man who awoke too early in the darkness, while all the others were still asleep. His gigantic efforts in the realm of what we now call science tragically failed to disturb his fellows from their slumbers. Only by his painting did he rouse them to their senses.

The dominant pattern of his life shows Leonardo, through his own isolated mental exertions, tracing out the path from art through the experimental observation of nature to the new outlook of science. As one follows him through the sequence of his notebooks one is struck by the early date of his efforts to analyse the phenomena of perspective. When Leonardo defined perspective as 'a function of the eye' he set himself the task of systematic observation of matters ranging from the distant stars and their transmitted light to the terminations of the optic nerve in the brain. In this way were born his extensive studies of the properties of light, optics and the anatomy of the eye, as well as his early interest in the anatomy of the brain.

A second line of approach to anatomy arising from Leonardo's artistic vision lay inherent in his definition of the purpose of art; this is to paint 'man and the intention of his soul' in terms of the 'attitudes and movements of the limbs'. The pursuit of this goal led him to analyse the postures and gestures of men's bodies in terms of their mathematical and mechanical laws. It led him also to make his first examinations of the mechanical instruments responsible for those gestures and attitudes; and so he dissected the human body, not only to reveal the forms of its muscles but to trace the source of their forces back to the spinal cord and brain. Such work was well under way during his first long sojourn in Milan (1482-99) when his notebooks already contain studies of the brain and cranial nerves, and his experiments on the spinal cord of the frog. In this period, too, he summarized his knowledge into a Treatise on Painting and the Human Figure, the one fragment of his work which was destined eventually to break through the shadows into publication.

There can be little doubt that these preliminary anatomical ventures opened to Leonardo's view the challenge of fresh worlds to conquer such as the vascular system and the abdomino-thoracic viscera. These parts of the body as well as detailed explorations of the muscles, bones and nerves occupied him during the second phase of his anatomical work in Florence in the years 1500-6. This period coincides with the shift of his interest from anatomy as subservient to art, to anatomy as the expression of a scientific urge. During these years he united both forms of his striving into the greatest of his visions, the one of the destruction of life, the Battle of Anghiari, the other of its creation, the Mona Lisa. 


\section{Leonardo da Vinci's Influence on Renaissance Anatomy}

Leonardo now entered the third phase of his study of the human body in which he attempted an analysis of its forces, its physiology. During this period, once more in Milan (1506-12) he joined his efforts with those of a professional anatomist, Marcantonio della Torre. During these years he sought to develop his favourite analogy between the forces of the macrocosm of the universe and the microcosm of man. It was too early for him to distinguish the truth from the falsity in this ancient comparison, and in its pursuit Leonardo missed the simpler mechanical truth, central to all human physiology, the circulation of the blood. Yet it was typical of his vision that he saw the lines of movement of the blood in the aorta as similar to those of the water in rivers, and that he confirmed these by the same experimental methods, so introducing the marker principle into experimental physiology. Here, as in all his physiological experiments (with but one exception), he made a model of the conditions he wished to investigate, and the aorta was only a particular example of fluid movement through a pipe. Marking the movement of the fluid by grains of panic grass, he observed its eddies and drew them with an accuracy which it remains for twentieth-century physiologists to confirm. ${ }^{1}$

There is no doubt that Leonardo intended to produce a Treatise on Anatomy. Apart from the orderly arrangement of certain sections we have his own word for it in the Treatise on Painting. It would appear, too, that he had this in mind when working with Marcantonio della Torre during the winter of 1510 when he 'looked to finish all this anatomy'.

Marcantonio della Torre is one of those through whom Leonardo's anatomical work might have exerted some contemporary influence. He himself was an anatomist of high repute. Vasari describes him as 'one of the first as I have heard say, who began to apply the doctrines of Galen to the elucidation of medical science, and to throw true light on anatomy which up to that time had been plunged in the almost total darkness of ignorance. In this,' he continues, 'he was wonderfully aided by the talent and labour of Leonardo, who made a book drawn with red chalk and annotated with the pen of the subjects which he dissected with his own hand and drew with the greatest diligence.'2 Leonardo continued working with della Torre until the young man died in I5I I. Both Vasari and Paolo Giovio refer to della Torre as having written anatomical works, but none has come down to us. One wonders how much these contained of Leonardo's labours; and what kind of influence had this work exerted that della Torre should have been so well spoken of to Vasari nearly fifty years after his death.

Another gifted contemporary of Leonardo who was in a position to vouch for some of his anatomical achievement was Luca Pacioli. These two worked together for some years in Milan before the downfall of the Duke, Ludovico Sforza. At this time Leonardo drew some sixty figures for Pacioli's work, $D e$ Divina Proportione, a treatise devoted to geometry in relation to architecture. In this work he illustrated the proportions of the human body by the Vitruvian figure of a man inscribed in both a square and a circle. It was with Pacioli that Leonardo began his geometrical researches, and from him he learnt how to manipulate mathematical roots; and it is to Pacioli that we owe the information 


\section{Kenneth D. Keele}

that by 1498 Leonardo had completed a book on The Human Figure. However, on human proportion there is relatively little in the Treatise on Painting.

In October 1518 towards the end of his life in Amboise, Leonardo showed some of his anatomical manuscripts to Cardinal Luis of Aragon.

This gentleman [wrote the cardinal's secretary] has written of anatomy with such detail showing by illustrations the limbs, muscles, nerves, veins, ligaments, intestines, and whatever else there is to discuss in the bodies of men and women, in a way that has never yet been done by anyone else. All this we have seen with our own eyes. He has also written of other matters, which he has set down in an infinite number of volumes all in the vulgar tongue, which if they should be published will be profitable and very enjoyable. ${ }^{8}$

At this time Leonardo was paralysed in the right hand as a result of a stroke. It was obvious that he could never himself complete the labour of publication, and that this task would fall to Leonardo's favourite pupil, the young Francesco Melzi, then some twenty-six years old. When Leonardo died in 1519, Melzi became his heir, and so brought back those precious volumes to his villa at Vaprio near Milan. There he worked on them for the rest of his life endeavouring to compile a worthy Treatise on Painting out of the mass of scattered notes, well over 5000 sheets of them. Thus these volumes were treasured by Melzi until his own death in 1568 , by which time he had not been able to complete his own task, many chapters of his compilation remaining uncompleted. During these years, however, Leonardo's notebooks were not kept from those capable of appreciating them; these (a very limited company of men) Melzi invited to inspect them.

The fact that these notes were not published during Melzi's lifetime must have depended on various factors, of which their incomprehensibility was the chief. This would lie at three levels; first that of reading the script. As is well known, Leonardo wrote left-handed, from right to left of the page. This in itself would not raise insuperable difficulties. But it was only one of Leonardo's oddities as a writer. Richter, who succeeded in transliterating and translating so many of Leonardo's notes for the first time in $188_{3}$, was under no illusions with regard to the difficulty of the enterprise. In his preface he writes: 'That, notwithstanding this eagerness to possess the Manuscripts, their many contents remained a mystery, can only be accounted for by the many and great difficulties attending the task of deciphering them.'4 Not only did Leonardo shape many letters of the alphabet in his own fashion, he fused words together, and divided them up equally arbitrarily; and his writings are devoid of punctuation of any sort. In addition he built up a set of his own short-hand terms. One has only to try to decipher short passages to appreciate the formidable nature of the task.

A second level of incomprehensibility lay in the intellectual nature of the content of the manuscripts, assuming their successful decipherment. For over a century now we have been helped by the fact that many of Leonardo's basic ideas were 'modern' and are thus easily comprehensible to us. This was, of course, far from being the case to Melzi and his companions. On the contrary, during the sixteenth century, many of Leonardo's repetitive tentative gropings towards mechanical solutions of cosmic and human problems must have appeared not 


\section{Leonardo da Vinci's Influence on Renaissance Anatomy}

only incomprehensible, but if penetrated, outrageous. It cannot have been far from the thoughts of good citizens like Melzi and his friends that such speculations were of so blasphemous a nature as to raise the literal truth of the cry, 'publish and be damned'. Vasari's reference to Leonardo as heretical, and more a philosopher than a Christian shows how real this danger was in $\mathbf{1 5 5 0 .}$

A third level of difficulty in interpretation lay in Leonardo's strongest claim to originality-in his power of visualizing his problems, thinking and expressing his thoughts in drawings rather than words. Whole sheets of his thoughts consist of wordless picture-sequences which like his words were arranged from right to left.

Of all subjects, it is true, these obstacles would apply least to anatomy. But when one realizes that here Leonardo was as concerned as much with the function of organs as with their structure, one can see that even the anatomical drawings, and those of his last years in particular, would be incomprehensible to almost anyone except possibly another anatomist of the calibre of Vesalius.

Thus when Melzi invited those capable of appreciating them to inspect Leonardo's notes, it was a small band indeed who were qualified to do so. Certain persons we do know, obtained direct or indirect access to Leonardo's notes. It is relevant to the subject of his influence on Renaissance anatomy to see how far these men overcame these obstacles and disseminated his views. Of these men Francesco Melzi himself must be mentioned first.

Melzi, more than any man then living, was best placed for the task of editing Leonardo's cryptic notes. He had been Leonardo's constant and trusted companion for over ten years before his death. He had assisted Leonardo during those years when he was hoping to complete his anatomical work in Milan; he had accompanied him to Rome, and there seen Leonardo's frustration and prohibition from anatomical work. He had witnessed Leonardo's evident concern for publication of his anatomy whilst living at Amboise. Yet he achieved nothing in this regard. Why?

The answer to our question emerges from a consideration of what Melzi did accomplish in this way during his life. There is no doubt that he did appreciate his particular responsibility with regard to Leonardo's manuscripts; nor is there any doubt that he set out to fulfil his task with devoted single-mindedness. As an artist he concentrated his energies on the Treatise on Painting, endeavouring to make this the point of departure from which to include all the various aspects of Leonardo's work. However, Melzi was overwhelmed by the mass of material which came to light. Apart from the difficulties of comprehension already mentioned, Melzi evidently found himself floundering in a sea of facts, figures and fancies which he was never able to master. Considering that he had some eighteen volumes of notes to deal with, this is perhaps excusable. By the end of his life, in 1568 , after some forty years of struggle, he had compiled a huge series of 944 short chapters selected from Leonardo's works. These were still in confusion, incomplete, and unpublished.

In order to achieve even this, Melzi had employed at least two assistants. These three persons must have systematically explored many of Leonardo's sheets; for their purpose went beyond that of a practical Treatise on Painting, to 


\section{Kenneth D. Keele}

include Leonardo's work on optics, geology, botany-but not apparently anatomy.

Another artist known to have had access to Leonardo's manuscripts was Albrecht Dürer. In ${ }_{1505}$ Dürer went to Venice to find out what the Italians could teach him on the subjects of perspective and human proportion. His search seems to have led him to Luca Pacioli, Leonardo's friend, whom he found at Bologna. It is possible that Dürer met Leonardo there. Whether this were so or not, Leonardo's influence on Dürer is revealed by the discovery of several sheets containing copies of Leonardo's notes on dragons, horses, and anatomy: ${ }^{5}$ these last consist of drawings of the bones and contours of the arm of a monkey and a human being. Several of Dürer's notes suggest too an acquaintance with Leonardo's Treatise on Painting. Leonardo's influence on Dürer's studies in human proportion has been substantiated by Panofsky. ${ }^{6}$

If such evidence of contact should raise hopes of finding a dissemination of Leonardo's anatomical advances through Dürer they fail to fulfil their promise. In spite of his enthusiastic studies on the proportions of the human body, Dürer performed little, if any, scientific anatomy. Once he does produce an anatomical drawing amongst his notes; a skeleton of primitive crudity. ${ }^{7}$ The well-known drawing, Memento Mei, showing Death as a skeleton on horseback also reveals his crude anatomical knowledge. Neither drawing reaches the standard of the early Leonardo study of the arm, of which he had made a copy.

The University of Pavia played a large part in Leonardo's life. Here he associated with professors of mathematics, anatomy and medicine; for such were Pacioli, Fazio Cardano, Marcantonio della Torre, and Girolamo Cardano. Fazio Cardano had in $\mathbf{1 4 8 2}^{4}$ translated John Peckham's Perspectiva Communis, a work on optics which in Leonardo's hands gave origin to a lifetime's research. Fazio is mentioned several times in Leonardo's notes. To these he must have had access both during Leonardo's lifetime and afterwards, for Fazio survived him by five years.

Though there is no evidence that the elder Cardan utilized Leonardo's notes other than by personal contact with his colleagues in Pavia this opinion does not apply to Fazio's illegitimate son Jerome Cardan. Born in 1501 , Jerome led a tempestuous life which, on its upward curve reached the professorial chair of medicine at Pavia in I547, and the publication of his De Subtilitate Rerum in $155 \mathrm{I}$. It is difficult to believe that so gifted a man, one who moreover had known Leonardo from his childhood, should fail to show an interest in those volumes in Melzi's devoted care at near-by Vaprio. And there is much evidence that he did know of them. In his descriptions of the camera obscura, in his interpretation of fossil formation, and in his account of the vacuum produced by the condensation of the atmosphere to form clouds and rain, Gardan betrays so close a relationship to Leonardo's thoughts that it is accepted by many that his contact with them was direct. Even the universal joint and the 'Cardan shaft' are to be found in Leonardo's notebooks. But Jerome Cardan was interested in the applications of mathematics to natural phenomena, an interest that included astrology and medicine; he seems to have been little concerned with anatomy, whether that of his personal acquaintance Leonardo or of the brilliant foreigner 


\section{Leonardo da Vinci's Influence on Renaissance Anatomy}

Vesalius. Cardan's attitude towards both these great anatomists is revealed in his allusion to them in the chapter on painting in his De Subtilitate. Here his comparison of the arts reflects that of Leonardo in his Treatise on Painting:

Painting [writes Cardan] is the most subtile of all mechanical arts, and the most noble. Painting creates more admirable things than poetry or sculpture; the painter adds shadows and colours and joins to these a speculative discipline. It is necessary for the painter to have a knowledge of everything because everything is of interest to him. The painter is a scientific philosopher, an architect, and a skilled dissector. The excellence of his representation of all the parts of the human body depends on this. This was begun some time ago by Leonardo da Vinci, the Florentine, and all but perfected by him. But this work never had such a craftsman, such an investigator of the natural parts, as Vesalius. ${ }^{8}$

One other contact of significance with Leonardo's notes is related by Vasari, who tells us that some writings of Leonardo, 'written with the left hand backwards, which treat of painting', were in the hands of a certain painter who visited him in Florence. Vasari tells how this man was taking the manuscript to Rome to get it printed. What happened to it after that no one knows. The story proves that some of Melzi's visitors were not content merely to examine Leonardo's manuscripts. How many disappeared from Melzi's villa even before he died?

Perhaps the most important of those who availed themselves of access to Leonardo's notes was the artist-writer, Giorgio Vasari. He, in his short Life of Leonardo, did more for the preservation of his name as an anatomist than any. It is obvious that Vasari could not appreciate the scientific value of the sheets of anatomical drawings which he saw; he had neither the time nor the knowledge to do so. But he was intelligent enough to sense their importance: 'Whoever succeeds in reading these notes of Leonardo', he wrote, 'will be amazed to find how well that divine spirit has reasoned of the arts, the muscles, the nerves and veins, with the greatest diligence in all things.'

The impression gained by Paolo Giovio was very similar; he seems to have been the only contemporary physician to write appreciatively of Leonardo's anatomical work. As a pupil of Marcantonio della Torre during the years when he was collaborating with Leonardo, Giovio would be in a good position to judge of Leonardo's methods. In 1527 Giovio wrote of Leonardo:

In order that he might be able to paint the various joints and muscles as they bend and extend according to the laws of nature, he dissected in medical schools the corpses of criminals, indifferent to this inhuman and nauseating work. He then tabulated with extreme accuracy all the different parts down to the smallest veins and the composition of the bones, in order that this work, on which he had spent so many years, should be published from copper engravings for the benefit of art.9

Even the physician Giovio, though he may well be recalling work done at Pavia with della Torre, makes no reference to the scientific nature of Leonardo's anatomy; he notes only its artistic value. This undoubtedly reflects contemporary opinion in general.

With all the vectors pointing towards Leonardo's influence in the field of artistic anatomy we are stimulated to examine the more closely Leonardo's one publication, the Treatise on Painting. 


\section{Kenneth D. Keele}

This Treatise is first mentioned by Luca Pacioli in a letter written to the Duke of Milan in 1498. 'Leonardo', writes Pacioli, 'with all diligence has finished his praise-worthy Book on Painting and Human Motion.' What happened to this, the most personal version of the Treatise on Painting? Was it completely lost, or did some manuscript copies circulate alongside the massive but still incomplete compilation of Melzi and his assistants? Whatever happened, the long version of the Treatise was not published until I8I7, whilst the short version appeared in Paris in 1651 .

Meanwhile, in 1542, Benvenuto Cellini, ardent among other enthusiasms in his admiration of Leonardo, whilst he was employed in Paris bought a manuscript in Leonardo's distinctive script from a poor gentleman. He describes it as containing sections on sculpture, painting and architecture, and he specially praises that on perspective. He does not, however, mention anatomy. It may be that the section on painting to which Cellini refers was the Treatise on Painting. If so, it was here combined with other parts of Leonardo's notes.

Some time before ${ }_{1584}$ the artist Lomazzo describes a version of the Treatise on Painting in Leonardo's peculiar handwriting, and Ambrosio Mazenta, from his description, seems to have seen the Treatise some time before $163 \mathrm{I}$.

In the Elmer Belt Library of Vinciania in Los Angeles there are twenty-three copies of manuscripts of the short version of the Treatise. As Steinitz remarks, 'each manuscript is important as a carrier and disseminator of Leonardo's message' ${ }^{10}$ These circulated in Rome, Urbino, Milan, Padua, Florence, Venice, Bologna, Cortona and Paris, during the sixteenth and first half of the seventeenth centuries. Enclosed in such copies of the Treatise were Leonardo's observations on anatomy.

The anatomical chapters of Leonardo's Treatise on Painting have received little attention. This is quite understandable since they are so overshadowed by his far greater and later, anatomical achievements. Nevertheless, it has to be remembered that these anatomical observations, modest as they are, reveal a concept of the human body as revolutionary for the time as any of Leonardo's productions. One has only to compare them with the traditional anatomy of Mondino to see this. Moreover, these anatomical chapters circulated widely in northern Italy in the decades following Leonardo's death. That they continued to exert considerable influence is demonstrated by their eventual publication, 132 years later, in 1651 .

Chapters dealing with anatomical matters are scattered widely throughout the Treatise. They may be grouped under four headings: Attitudes and Gestures; Equilibrium and Movement; Proportions of the Human Body; and Descriptive Anatomy. They total about 120 out of 355 chapters in the first English edition of the Treatise on Painting (from which all quotations are taken). ${ }^{11}$

The outlook of these chapters is, perhaps, best summarized in Leonardo's own words: 'When you understand the make of a human body, its members, Jonctures, and the several positions these are capable of, apply yourself to the study of motion.' Attitudes are discussed in relation to the prominence of muscles ... 'A painter will look with contempt on the manner of some ignorant painters who in all sorts of attitudes do always make the same 


\section{Leonardo da Vinci's Infuence on Renaissance Anatomy}

muscles appear, in the arms, back, stomach, and other parts.' Again, attitudes are analysed in relation to the expression of emotions:

All the figures in a painting ought to be in an attitude suitable to the subject they represent; so that in viewing them one may easily know what they think and what they would say. To assist your imagination in this suiting the attitudes to the figures, consider attentively the gestures of mutes, who express the thoughts and conceptions of their mind by the motions of their eyes, hands, and whole body. . . .

The relation of attitudes to age is described:

To represent an old man standing, you must give him a dull, indolent attitude, with slow motions, his knees a little bent, his feet straddling, his back crooked, his head stooping forwards, and his arms rather folded than spread too wide.

These descriptions are of exemplary clinical brevity and accuracy. The movements of the shoulders, hips, and neck are described as 'more variable than any other Jonctures of the body; their motions being more numerous and diversified than those of any other part. But of these I propose a particular Treatise.' Here, as on several other occasions in the Treatise, Leonardo promises further studies which we know him to have carried out.

Equilibrium and Movement receive over seventy chapters in the Treatise. They also form the subject of seventeen illustrations in the book. All Leonardo's discussion of these subjects is governed by his great general principle: 'All motion proceeds from the loss of equilibrium, that is of equality of balance. This must always cease e'er motion can commence; and ever the further any body is removed from the equilibrium the quicker and more violent is its motion.' This observation leads him on to an analysis of the movements of the body in terms of a shifting centre of gravity: 'The stretching out of an arm drives the equilibrium of the body into that foot which sustains the whole weight; as is seen in those who, with arms outstretched, can walk upon a rope.'

His particular interest in the movements of the arms led him to make the further comment on their relation to balance:

A figure standing firm on its feet makes an equilibrium of all its members around the central line on which it is sustained. A figure therefore thus steady and thus balanced, stretching one of its arms out from the body, must at the same time shift so much of its weight to the opposite side as is equal to that of the extended arm. This must be understood of every part in general, sallying out beyond ordinary from its whole.

Leonardo was treating the human body as an instrument of movement, governed, even in the expression of its deepest emotions, by mechanical laws. Such a mechanistic concept of human movement brought an entirely 'new look' to human anatomy and physiology. It was as revolutionary an outlook on the problems of the human microcosm as was Copernicus' new view of the solar macrocosm. Shorn even of the vast range of his anatomical discoveries Leonardo here shows something of his creative anatomical genius.

The third group of anatomical observations, those on the Proportions of the Human Body is surprisingly small, some ten chapters only. It is difficult to account for this except by the suggestion that Leonardo already planned an independent treatise on this subject. This possibility is endorsed by his comment 


\section{Kenneth D. Keele}

at the end of the chapter on the different proportions in the body of a man and a child: 'For the rest we shall treat of them when we come to consider the Proportions of all the Parts of a Human Body.'

That Leonardo had indeed finished a detailed study of human proportions by 1498 is consistent with the dating of those many drawings on the subject now at Windsor. It is confirmed by the young man, Guericus, who published an account of Leonardo's own particular system of human proportions in 1504 . This, it would appear, was just one more example of Leonardo's influence being demonstrated by the utilization of his unpublished work by another.

Of descriptive anatomy the Treatise on Painting contains relatively little, some twenty-two chapters only. These are almost entirely devoted to descriptions of bones, muscles and joints. The points made are for the most part simple, referring to the shape of joints in flexion and extension, the prominences caused by muscle tendons or bellies, etc. Some, however, deal with specific problems such as the movements of the hip or shoulder joint, the flexion and extension of the elbow joint as it affects the 'adjutorium and the two fucils', i.e. the humerus and the radius and ulna. This and the movements of the ankle are illustrated. There is a description of the sesamoid bones of the body, numbering eight; 'in each shoulder one, as many in each knee, and two in each foot, under the first Joncture of the great toe, towards the heel. And let it be observed that these bones always grow extremely hard as the person draws near to old age.' The muscles of the abdomen are interestingly but vaguely described; and there is a curiously detailed description of the pronator quadratus which 'rises in the middle of one of the fucils of the arm and terminates in the middle of the other fucil; its form is square, its breadth three inches and its thickness one and a half. ... These specific anatomical descriptions are inevitably marred by lack of comprehension on the part of the copyist.

Of all joints, Leonardo was most interested in the shoulder, ending his description with the assurance that the matter will be further explained 'in my Treatise on Anatomy'. Here in this Treatise he describes the movements of the shoulder as

mostly simple; that is the arm, directed by them is usually carried either upwards or downwards, backwards or forwards. Though these motions may be said to be infinite, yet in effect does the arm in describing a circle on the wall show all the motions it is capable of. For every continued quantity being divisible in infinity, and this circle being a continued quantity produced by the motion of the arm around its circumference, it follows, of course, that the motions of the shoulder are infinite.

This concept of infinite circular movements Leonardo applied to other joints, to the wrists, fingers, toes, and above all to the spine. From such concepts of joint movement it becomes geometrically possible to construct a complex of bodily movements consisting of one circular movement upon another, the whole pattern building up to that of cycle on epicycle of infinite variety yet of fixed order. This corresponds to the Ptolemaic conception of the movements of the celestial bodies. Of this Leonardo was well aware, and later claims that he will show the body 'in the same order as was used by Ptolemy before me in his Cosmography ... in so far as it has local movement by means of its parts'.12 


\section{Leonardo da Vinci's Influence on Renaissance Anatomy}

Though Leonardo himself did not fully develop this concept, a Milanese artist who came across his treatise did, logically and systematically drawing its results in a set of extraordinary figures. These are to be seen in the Codex Huygens, a work written about 1570 by a Milanese artist, possibly Aurelio Luini, son of one of Leonardo's most notable students Bernardino Luini. This Codex also contains drawings of skeletons, studies of human proportions, and a series on the proportions of the horse which are certainly copied from lost manuscripts of Leonardo. In Panofsky's opinion it contains at least thirty-two copies of Leonardo's drawings, sixteen of which are otherwise lost. ${ }^{13}$

The Codex came to light in 1690 , being then bought from the wife of a Dutch artist by Constantine Huygens, secretary to King William III. It once more illustrates the existence of the widespread influence of Leonardo's anatomy amongst the artists of the sixteenth century.

We divided Leonardo's anatomical studies into three stages: early artistic exploration of the muscles, bones and joints, and their movements; topographical exploration and discovery; and that of physiological inquiry. It is clear that the last two scientific stages of his work withered away in the intellectual vacuum around them. Their traces gave birth to no more than the legend of Leonardo the Anatomist, the factual basis for which was hidden away, either in Melzi's villa in Italy, in Pompeo Leoni's scrapbooks in Spain, or in a castle in England. Only about 1780 , when William Hunter had seen the sheets at Windsor, did this legend regain its factual foundation.

Leonardo's first phase of artistic anatomy did not suffer so cruel a fate. It was as an artist that he successfully spread the roots of his anatomy into the studios of his fellows, where it lived on until it reached publication in 1651 , after which its influence soared. Its usefulness to artists was due to the science it brought into their art. Anatomy could not come into existence as a science without adequate techniques for recording its observations; these it needed as much as any other science; these the Treatise on Painting stressed, revealing itself in spite of its title as a scientific study of a mechanical and psychological instrument, the human body.

It was as an artist that Leonardo attempted the fusion of anatomy with medical science through della Torre. This attempt was itself a great peak reached from those first modest beginnings of anatomy in the botegas of Pollaiuolo and Verrocchio. The renaissance of anatomy could never have occurred without those long, distasteful hours of adventurous dissection and patient drawing. Without this artistic surge for knowledge the medical professors of anatomy, droning their prosings from a tainted Galenic text, could never have found a way of recording Galenic anatomical errors, let alone their corrections.

Leonardo was known throughout northern Italy as the artist-anatomist who had created the new science; he was the spearhead of the new creative anatomy. Death barred his experiment with della Torre from success. But the movement went on, particularly in Florence. Through Andrea del Sarto, Leonardo's anatomy reached his pupil Rosso Fiorentino, who himself planned an 


\section{Kenneth D. Keele}

anatomical treatise; and Rosso, with Perino del Vaga, found himself drawn into the unhappy textbook of anatomy compiled by Estienne and Rivière. ${ }^{14}$ Once more the fusion arose in the projected work on anatomy in which Michelangelo contemplated collaboration with Realdo Colombo.

These examples reveal how Leonardo had broken the hard ground of bigotry and prejudice which had buried anatomy for so many centuries; how he had stimulated the fusion of art and science in anatomical representation; and how he had prepared the tilth to receive the masterpiece of Vesalius and Calcar. In I543, when this was published, it was neither lost nor damned.

\section{REFERENCES}

I. KEeLe, K. D., Leonardo da Vinci on the Movement of the Heart and Blood, London, Harvey and Blythe, 1952, pp. $8 \mathrm{I} \mathrm{ff}$.

2. VASARI, G., The Lives of the Painters, Sculptors and Architects (1568), trans. by A. B. Hinds, London, Everyman, vol. II, pp. $156 \mathrm{ff}$.

3. MGCURDy, E., The Mind of Leonardo da Vinci, London, Jonathan Cape, 1932, p. 147.

4. RichteR, J. P., The Literary Works of Leonardo da Vinci, 1883, vol. I, p. xili.

5. Glark, Kenneth, A Catalogue of the Drawings of Leonardo da Vinci at Windsor Castle, Cambridge University Press, 1935, p. 107.

6. Panofsky, E., The Codex Huygens and Leonardo da Vinci's Art Theory, London, Warburg Institute, 1940, p. 115.

7. Conway, W. M., Literary Remains of Albrecht Dürer, 1889, Cambridge University Press, p. 237.

8. Gardan, J., Les Livres de Hierome Cardanus Médicin Milannois, Paris, I578, Bk. 17, p. 386.

9. Grovio, P., De Viris Illustribus (1527), trans. by J. P. Richter, The Literary Works of Leonardo da Vinci, 1939, vol. I, p. 3.

10. Steinitz, K. T., Leonardo da Vinci's Trattato della Pittura, Copenhagen, I958, pp. $45 \mathrm{ff}$.

I1. LeONARdo DA Vinci, $A$ Treatise of Painting, trans. from the original Italian, London, I 721 .

12. Vangansteen, O. C. L., Fonahn, A., Hopstogk, H., Leonardo da Vinci Quadernia d'Anatomia, Christiana, vol. I, p. 27.

13. Panofsky, E., op. cit., 1940.

14. Kellett, C. E., Perino del Vaga et les illustrations pour l'anatomie d'Estienne, Aesculape, 37, 74-89. 